\title{
Travelling Fires for CFD
}

\author{
JOAKIM SANDSTRÖM ${ }^{1,2}$, XUDONG CHENG ${ }^{1}$, MILAN VELJKOVIC ${ }^{1}$, ULF WICKSTRÖM ${ }^{1,3}$, and TIM \\ HEISTERMANN ${ }^{1}$ \\ ${ }^{1}$ Department of Civil, Mining and Environmental Engineering \\ Luleå University of Technology \\ 97187 Luleå, Sweden \\ ${ }^{2}$ Brandskyddslaget AB \\ Kungsgatan 12 \\ 65224 Karlstad, Sweden \\ ${ }^{3}$ Technical Research Institute of Sweden \\ Brinellgatan 4 \\ 50462 Borås, Sweden
}

\begin{abstract}
There are numerous methods in structural fire safety engineering to assess a time-temperature input for structural calculations in fire enclosures but there is very little on design fires for CFD calculations. This study is an attempt to explore a simpler form of design fire. The simplified approach consists of two main features, a travelling behaviour and a heat release rate specified by the user.
\end{abstract}

KEYWORDS: CFD, design fires, travelling fires, temperature, FDS.

\section{INTRODUCTION}

There are numerous methods in structural fire safety engineering to assess the time-temperature input for structural calculations in fire enclosures [1]. Many of these [2,3], are simple one-zone models with various levels of complexity and precision. Others are two-zone models [4-6] which can be used for larger, but still simple, geometries.

Since 2001 and the WTC investigations [7], computational fluid dynamics, CFD, has been a widespread method for solving performance-based fire design problems. Still, for structural fire safety, there has been little guidance on how to specify fire scenarios to use as boundary conditions for temperature calculations with CFD. The most common CFD code for fire design is Fire Dynamics Simulator, FDS, [8] developed at NIST (National Institute of Standards and Technology) and used in the WTC investigations. In this code there are a few methods to specify design fires

1. A surface with constant heat release rate,

2. A surface with an increase of heat release rate linearly or according to $\left(t / t_{\text {ref }}\right)^{2}$,

3. A radially spreading fire,

4. A flame spread model specified within the code, or

5. A ramped behaviour specified by the user.

The two first methods above assume a fire that does not move. This can be seen as unrealistic for most cases as the fire load usually is more evenly distributed. For large compartments where the fire area is smaller than the floor area due to lack of ventilation, the fire can be assumed to move in the compartment as the fire load is consumed. The third method is realistic but difficult to control and the fourth method requires a high level of competence in material and combustion behaviour and is therefore hard to use for design purposes. This study is an attempt to explore the fifth method and apply the concept of travelling fires as presented in [9-10] to CFD design fires.

The aim is to evaluate the overall hot layer gas temperature from FDS in large scale volumes against simpler models. This is a way of evaluating the concept of travelling fires in combination with FDS as a design tool.

\section{DESIGN FIRES}

In FDS the design fire can be specified with a known heat release rate. The design heat release rate is, in this study, specified according to Eurocode 1991-1-2, annex E Load densities [2].

FIRE SAFETY SCIENCE-PROCEEDINGS OF THE TENTH INTERNATIONAL SYMPOSIUM, pp. 1479-1488 
The fire is assumed to grow at a specified rate proportional to $\left(t / t_{\text {ref }}\right)^{2}$, until it reaches the maximum heat release rate of the fully-developed fire. The maximum heat release can be calculated based on ventilation [11] or heat release per unit area multiplied by the total floor area.

When approximately $70 \%$ of the fuel load is consumed, the heat release rate starts decaying linearly to zero in such rate that the integral of the heat release rate in the decay phase equals the remaining fuel.

\section{TRAVELLING FIRES}

For large compartments, it is very unlikely that a fire grows uniformly over an entire enclosure floor area [10]. Usually it starts at some point and then moves across the enclosure. The fire can move in different ways and cover different portions of the floor area simultaneously.

The concept of travelling fires is primarily developed to simplify, but keeping its quality of approximation, an input for a structural evaluation [12]. As the fire moves over one floor level, the gas temperature directly above the fire is very high and lower over areas where the fire is not active. In this way the fire input temperature to the structural analysis is deemed to be approximated in a realistic way. It is also possible to compare different fire scenarios within a reasonable computational effort.

\section{MIXING OF DESIGN AND TRAVELLING FIRES}

The concept of a moving fire is assumed and the floor in FDS is divided in small plates each of which is modelled as a separate burner. The user can control the burners to start and stop so that a design fire heat release rate is mimicked. The plates contribute with uniform heat release rate for as long as there is combustible material in the plate, or, in this case, the time specified by the user. This creates the same concept of a moving fire as in the concept of travelling fires although moving the input from direct thermal boundary condition to FEM calculation of structural elements to a heat release boundary condition in CFD calculations.

The results from the calculations can then be used as a part of the overall evaluation of the structural interface temperatures in the building.

\section{FDS}

FDS, or Fire Dynamics Simulator [8], is a computational fluid dynamics (CFD) code specialising on thermally driven flows such as fire flows. The development is an ongoing open source project coordinated by NIST, (National Institute of Standards and Technology) that was released in 2000 as a public domain code. In this report, FDS v5.5 was used.

The code solves the Navier-Stokes equation with the finite difference method. The code solves the turbulence using the large eddy approach and assumes all flows to be non-compressible. Radiation is solved using the finite volume method.

The surface temperatures are calculated using a one-dimensional finite difference solver. This assumption, that surface temperatures can be solved with a one-dimensional solver, works well for large uniform surfaces such as walls thus yielding fair temperatures in enclosures.

\section{METHOD}

The method for assessing temperatures in other models such as two-zone or the correlation derived by McCaffrey, Quintiere and Harkleroad [13] is to calculate the hot layer temperature. From FDS, a mean temperature for the hot layer is calculated. If the hot layer temperatures in these calculations show enough consistency, they are deemed reliable, and then structural interactions can be considered. Also, if the temperatures are consistent with results from models with more extensive testing for the temperature domain in large enclosures, the method could be applied to more detailed studies of temperature fields and structural interaction.

\section{Geometry}

The enclosure used in this study is a simple, hypothetical one storey open plan building with smoke ventilation through the ceiling. This geometry allows for comparison between two-zone models and FDS and to evaluate differences in the results. 
The building is $20 \mathrm{~m}$ by $40 \mathrm{~m}$ with a height of $10 \mathrm{~m}$. The four smoke ventilators are located equally spaced over the ceiling, each with a size of one square meter. On each of the four sides has a $2 \mathrm{~m}$ by $4 \mathrm{~m}$ door opening.

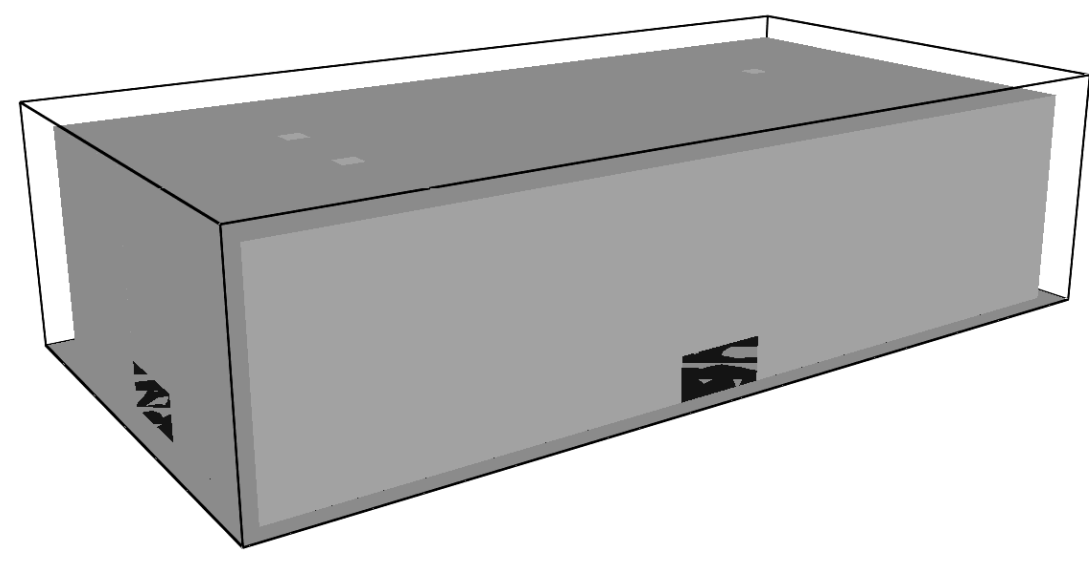

Fig. 1. Geometry of the hypothetical open plan building used in the study.

\section{Design Fire}

The comparison is made between

- A fire with the same fire area as the floor area but with limited the heat release per unit area.

- A fire with design heat release per unit area but with limitation in fire area.

- Travelling fires with different starting points and plate sizes.

The overall heat release rate in each of the calculations is built up to mimic a possible design heat release calculated with the method presented in Eurocode 1991-1-2, annex E [2]. Values used in the hypothetical design fire are shown in Table 1 and this gives a design heat release rate as presented in Fig. 2.

Table 1. Input values for design fire calculation.

\begin{tabular}{|l|l|}
\hline Fuel load & $500 \mathrm{MJ} / \mathrm{m}^{2}$ \\
\hline Heat release per unit area & $0.5 \mathrm{MW} / \mathrm{m}^{2}$ \\
\hline Maximum heat release & $95 \mathrm{MW}$ \\
\hline Reference time & $300 \mathrm{~s}$ \\
\hline
\end{tabular}




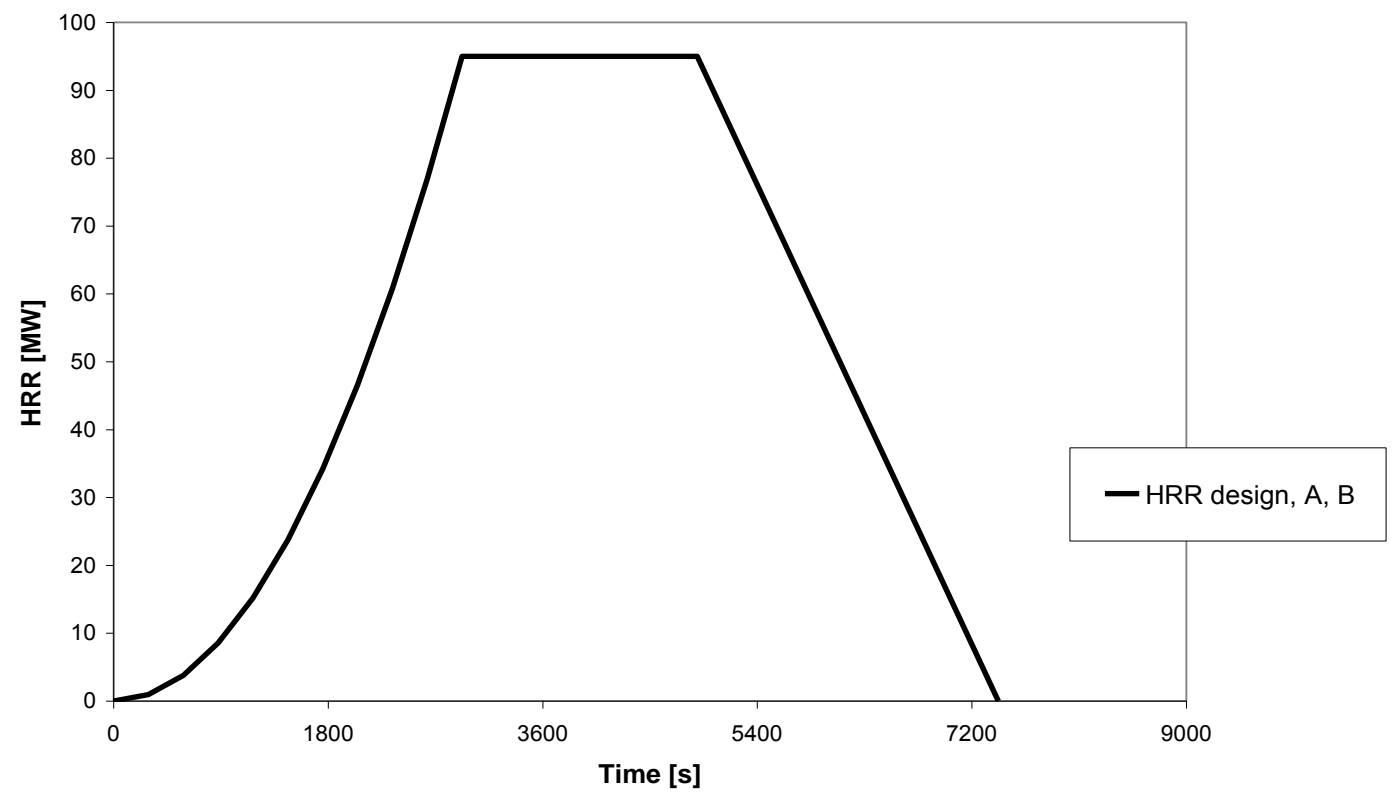

Fig. 2. Design heat release.

The floor area is then divided into smaller entities acting as separate plate burners that can be turned on and off by the FDS user. The plate burners are turned on at different times creating a larger and larger fire until the maximum heat release rate is reached and thereafter the effect is remained constant until the start of the decay phase. Each plate burns with a specified heat release rate per unit area and is activated for as long as there are any fuel load remaining on the plate. The plate activation progresses from a starting point specified by the user and continues to nearby plates. The plates then acts as burners with a specified heat release rate until the entire fuel load for that plate is burnt away. The plate burner is then turned off and other, nearby plate burners are turned on. This continues until the fire load for the entire floor is consumed.

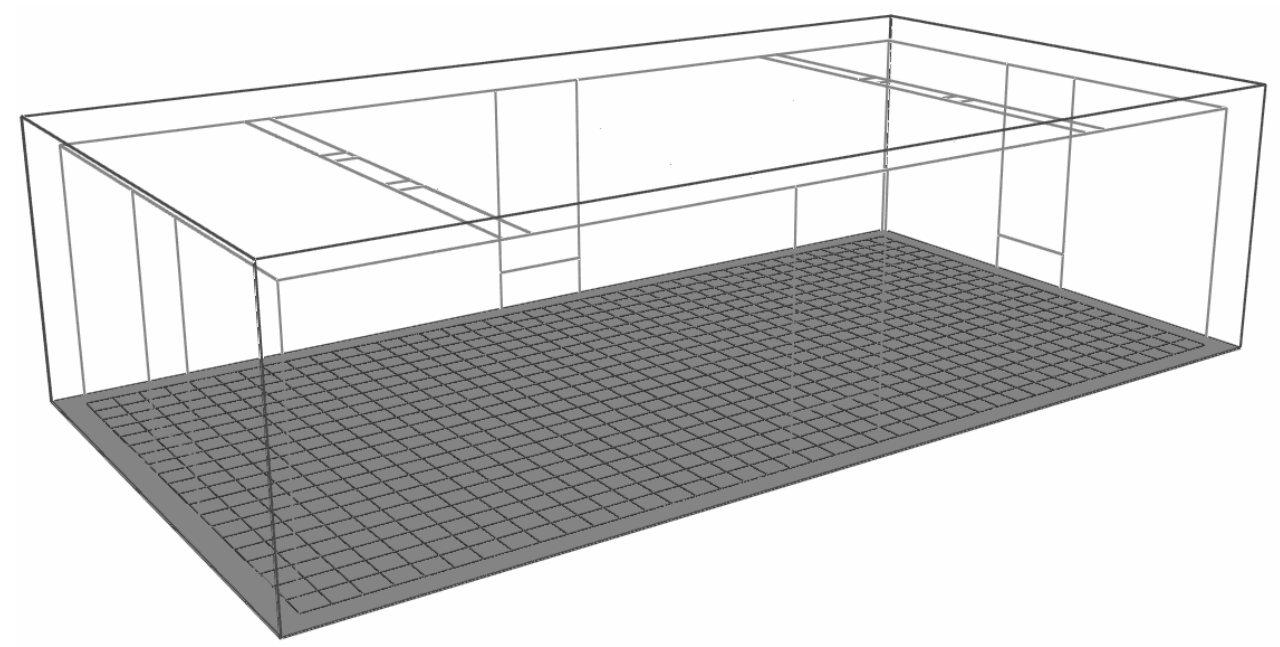

Fig. 3. Geometry in FDS with plate burners outlined on the floor.

To be able to process this large amounts of data, a pre-processor has been developed that can create input for travelling fires to be analysed with CFD. By specifying a starting point, size of the floor, heat release rate per unit area, fire load per unit area, fire growth rate and total max effect the code creates a segment of text to be used in the FDS input file. In this segment of text, each plate burner with its heat release rate and the starting and stopping time is specified. 


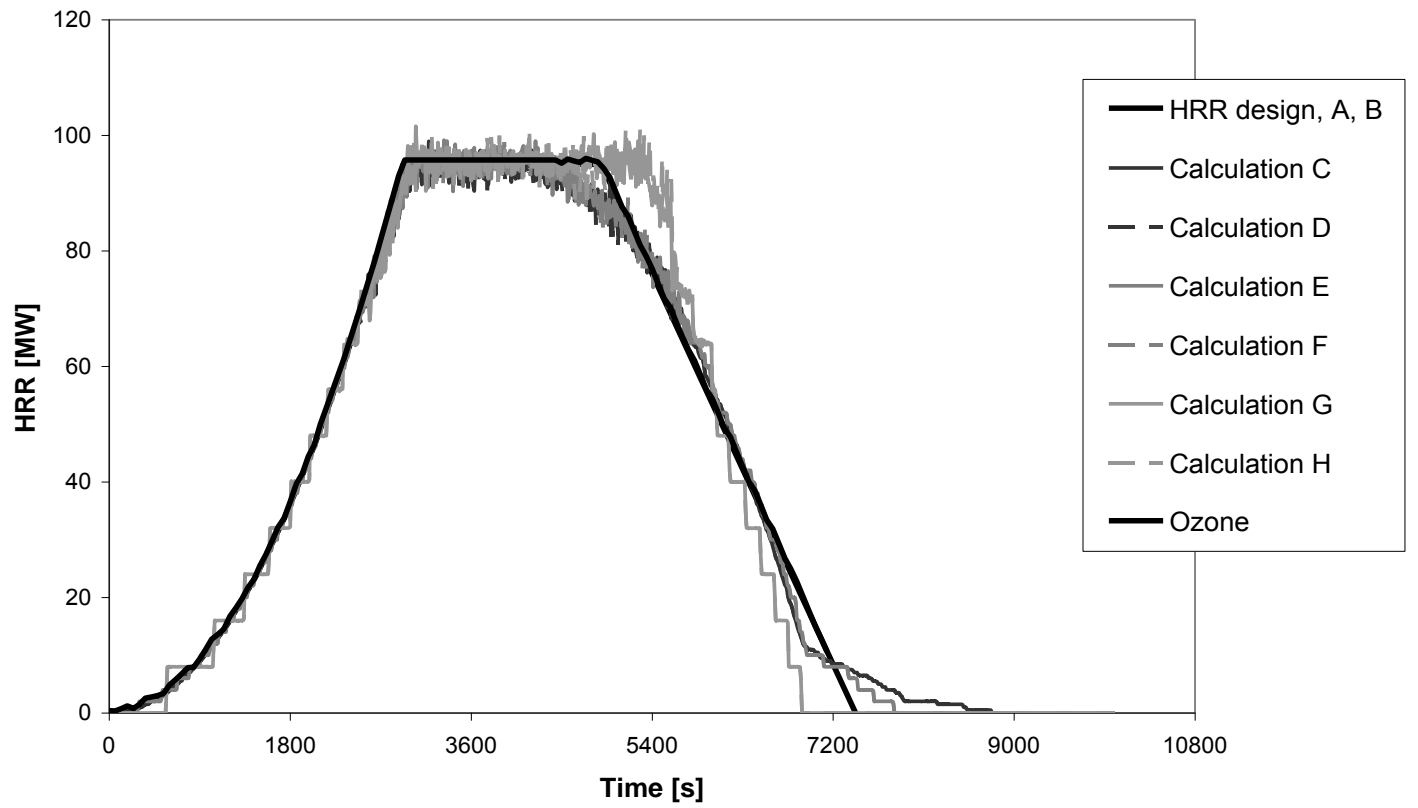

Fig. 4. Heat release rate in the different calculations.

\section{RESULTS}

\section{Design Heat Release Rate}

The heat releases from the calculations specified in Table 2 are compared in Fig. 4. As can be seen, the decay phase does not mimic the design fire exactly. This is due to the different starting times of the plate burners. However, as shown later, the result is only affected marginally by this.

The hot layer temperature is calculated as a mean value in the volume stretching over the entire ceiling and down to one meter below the ceiling. This is done using the statistics function incorporated in FDS [8].

\section{Sensitivity Study}

To obtain a grid independent result, a pre calculation was performed to evaluate a suitable grid size for the comparison. Four different calculations were performed assuming a grid cell size of $1 \mathrm{~m}, 0.5 \mathrm{~m}, 0.33 \mathrm{~m}$ and $0.25 \mathrm{~m}$. The fire in this study consisted of the simplest of the different fires, with a stationary plate burner covering the entire floor. 


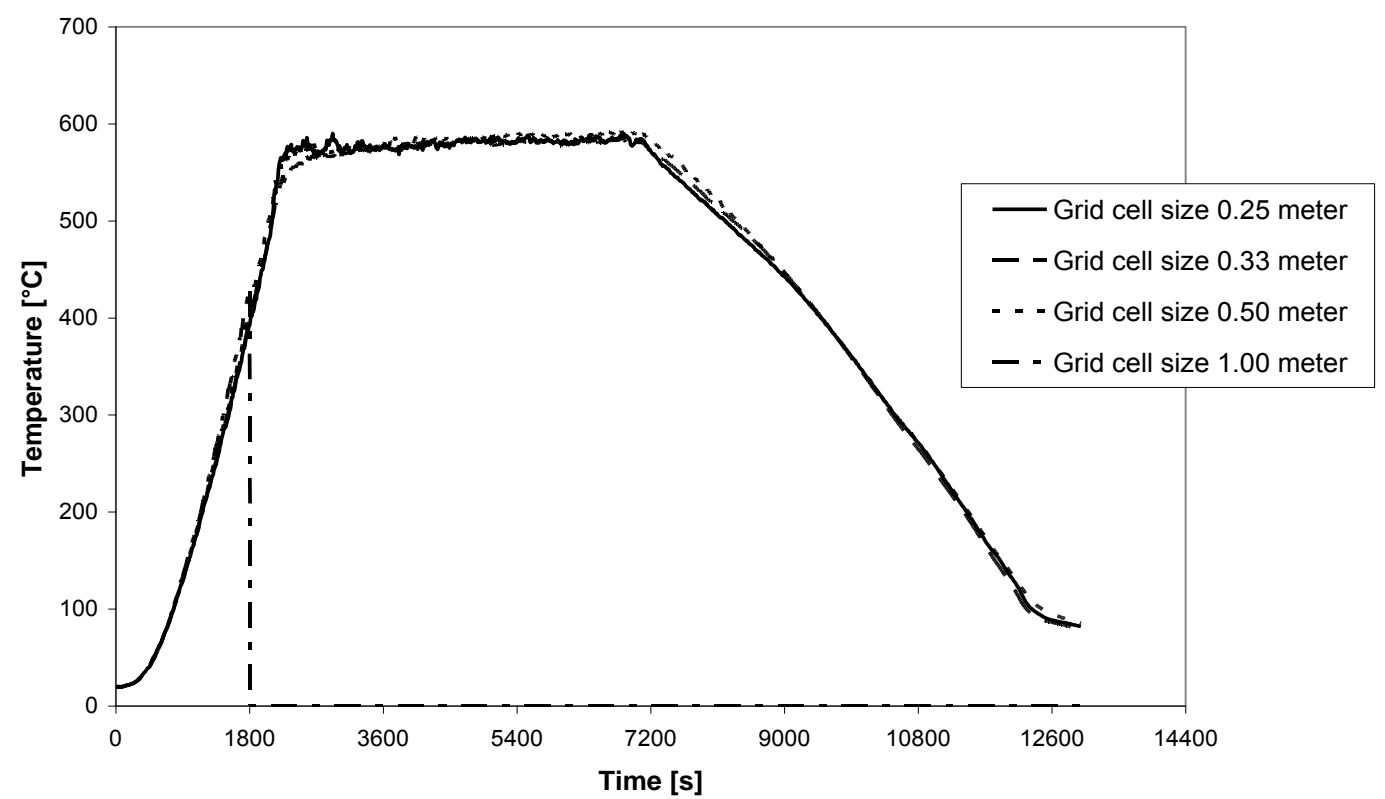

Fig. 5. Sensitivity study of the grid size.

The calculation with grid cell size $1 \mathrm{~m}$ stopped due to numerical instability. However, the rest of the calculations performed as intended and presented more or less the same temperatures. Based on this, a grid size of $0.5 \mathrm{~m}$ was decided to be sufficient.

\section{Comparison}

Four different travelling fires were compared with two fixed fires. The travelling fires with finite plates starts either from the centre of the room or from one corner.

The different FDS calculations performed are shown in Table 2. For the sake of reference, a two-zone calculation was performed with Ozone v2.2 [5].

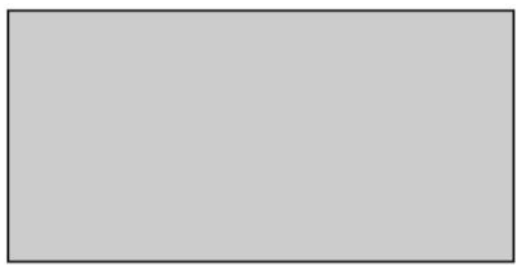

(a)

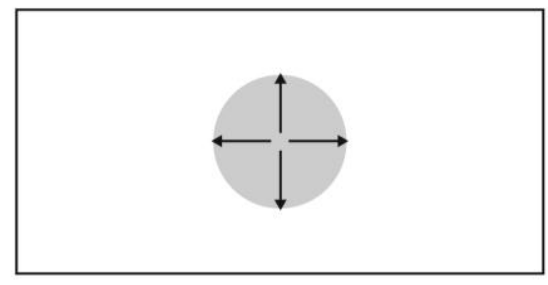

(c)

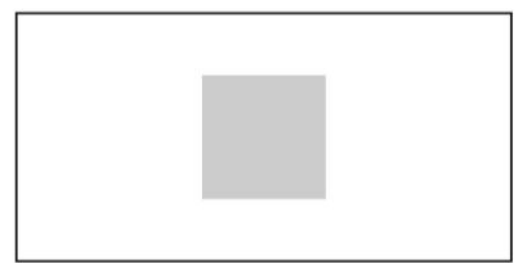

(b)

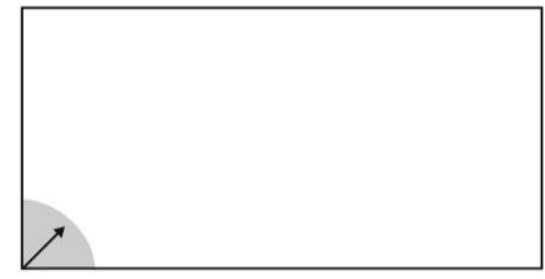

(d)

Fig. 6. (a) Fixed fire area when the floor area defines the fire size; (b) fixed fire area when the heat release per unit area defines the fire size; (c) a travelling fire with finite plate burners progressing from the centre of the room; (d) a travelling fire with finite plate burners progressing from one corner of the room. 
Table 2. Characteristic fire scenarios used in analysis.

\begin{tabular}{|l|c|c|c|}
\hline Fire type & Plate area & Starting point & Calculation \\
\hline Fixed fire - maximum area & $100 \%$ & - & $\mathrm{A}$ \\
\hline Fixed fire - maximum $\mathrm{kW} / \mathrm{m}^{2}$ & $12.5 \%$ & Centre & $\mathrm{B}$ \\
\hline Travelling fire & $0.125 \%$ & Corner & $\mathrm{C}$ \\
\hline Travelling fire & $0.125 \%$ & Centre & $\mathrm{D}$ \\
\hline Travelling fire & $0.5 \%$ & Corner & $\mathrm{E}$ \\
\hline Travelling fire & $0.5 \%$ & Centre & $\mathrm{F}$ \\
\hline Travelling fire & $2.0 \%$ & Corner & $\mathrm{G}$ \\
\hline Travelling fire & $2.0 \%$ & Centre & $\mathrm{H}$ \\
\hline
\end{tabular}

The temperatures in the hot layer from the different calculations are shown in Fig. 7.

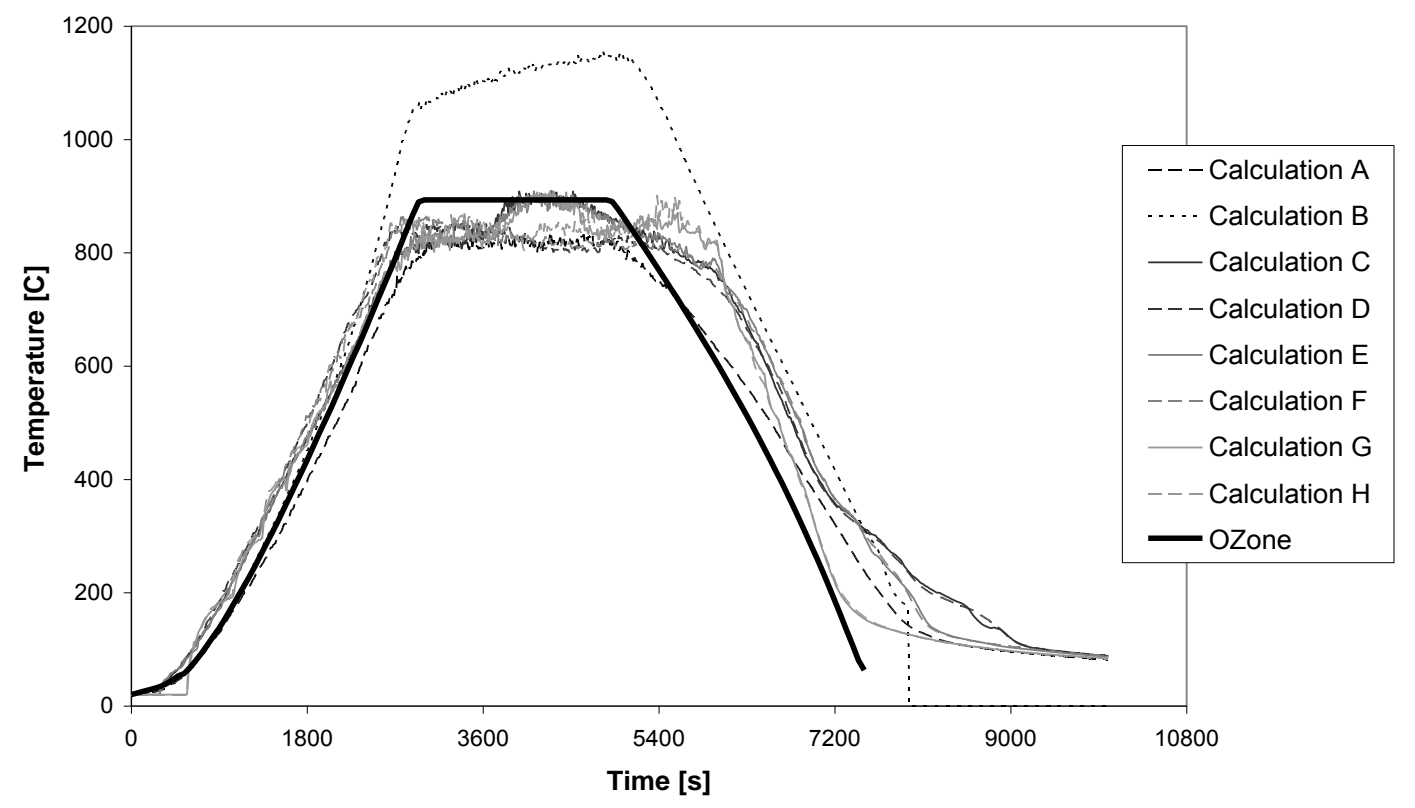

Fig. 7. Mean temperatures from the hot layer close to the ceiling.

\section{Design Temperature}

The temperatures reach a plateau in the fully developed fire phase. The temperature in the plateau phase varies slowly over time and can be considered more or less stationary.

The results from the CFD calculations show temperatures around $850{ }^{\circ} \mathrm{C}$ in the fully developed fire phase. Instead of assuming a most probable fire deterministically it is possible to statistically determine a probabilistic temperature distribution. To do this, the hot layer temperatures from all fires in the fully developed fire phase are evaluated statistically.

The probability density function of the temperatures from the fully developed fire phase of all calculations can be described using a Gumbel Type I distribution (see Fig. 8) with a covariance of $3.75 \%$. The percentiles from the data set are compared to a normal and Gumbel distribution to see which distribution fits the data set the best (see Fig. 9). This way a cumulative distribution for the temperature of the fully developed fire can be described as in Table 3. 


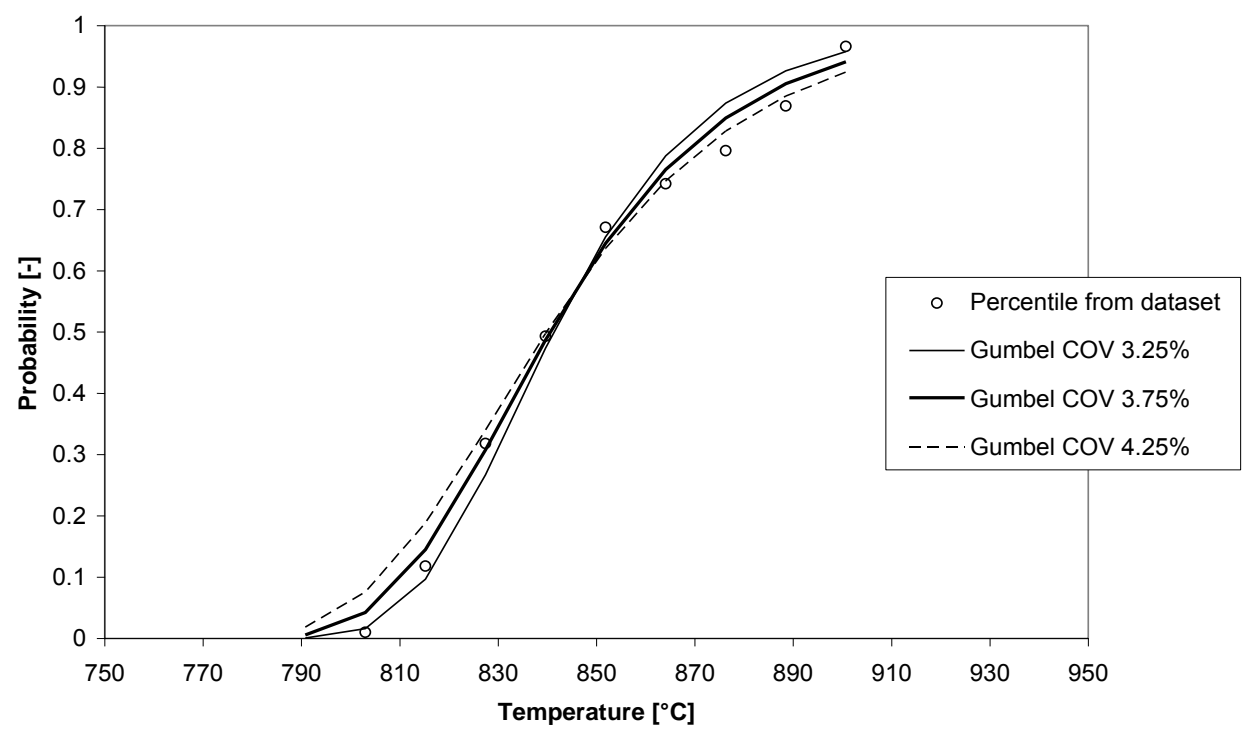

Fig. 8. Cumulative Gumbel Type I distribution with different covariances.

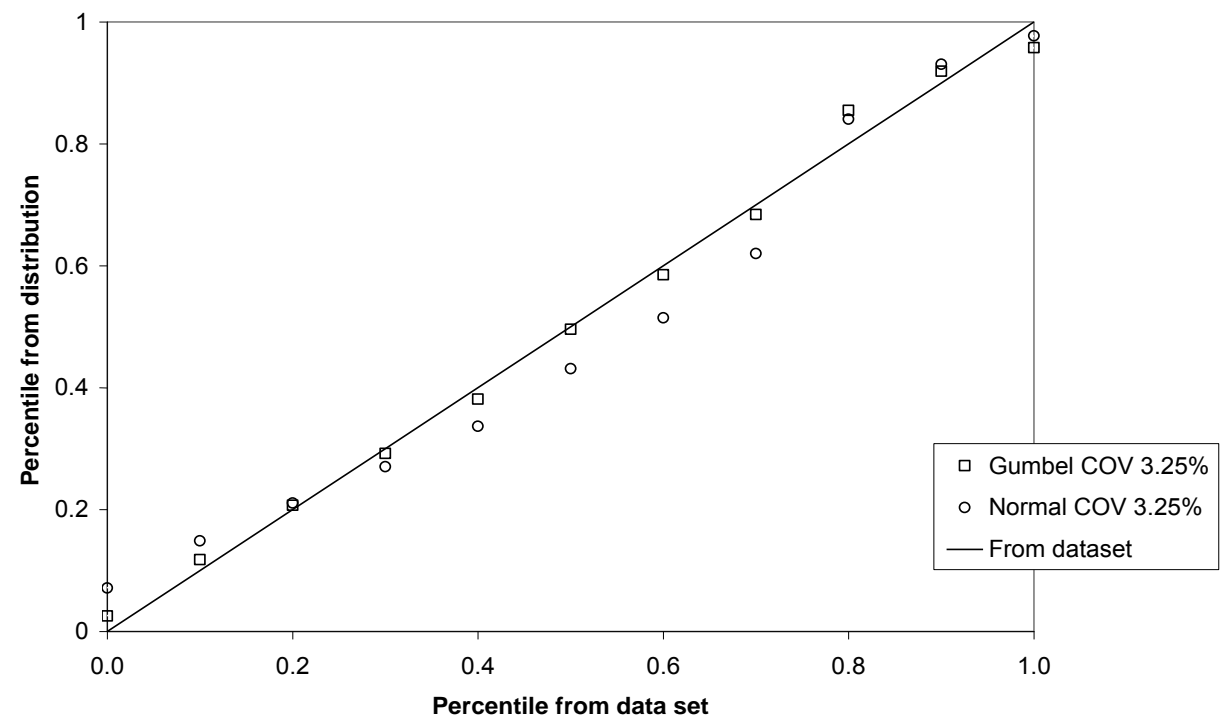

Fig. 9. Comparison between normal and Gumbel distribution given the mean from data set and covariance from Fig. 8.

Table 3. Mean temperature and covariance of temperature distribution in the fully developed fire phase.

\begin{tabular}{|l|c|c|}
\hline Data & Mean temperature $\left({ }^{\circ} \mathbf{C}\right)$ & COV $(\%)$ \\
\hline Temperature & 845 & 3.75 \\
\hline
\end{tabular}

By calculating the mean value of all the travelling fire calculations and using the covariance from the previous table it is possible to assess a time-temperature relation for the hot layer temperature not likely to be exceeded with a statistical certainty of some level for each time step.

The JCSS [14] recommends a target reliability index of $\beta=4.2$ over a reference period of one year for a building with moderate consequence of failure and normal relative cost of safety measure. The Natural Fire Safety Concept report [15] gives a probability of fire that could lead to structural collapse of $p_{f i}=4.0 \times 10^{7}$ per square meter floor area, $A_{\text {floor }}$. Since the temperature approximately follows a statistical distribution it is possible to assume $p_{T}$, probability that the design temperature will be exceeded from $A_{\text {floor }} p_{f i} p_{T}=\Phi(-\beta)$. 
As $A_{f l o o r}, p_{f i}$ and $\beta$ is known $p_{T}$ can be calculated to 0.042 and the percentile for the temperature not to be exceeded from the Gumbel distribution of each step is $1-p_{T}=95.8 \%$.

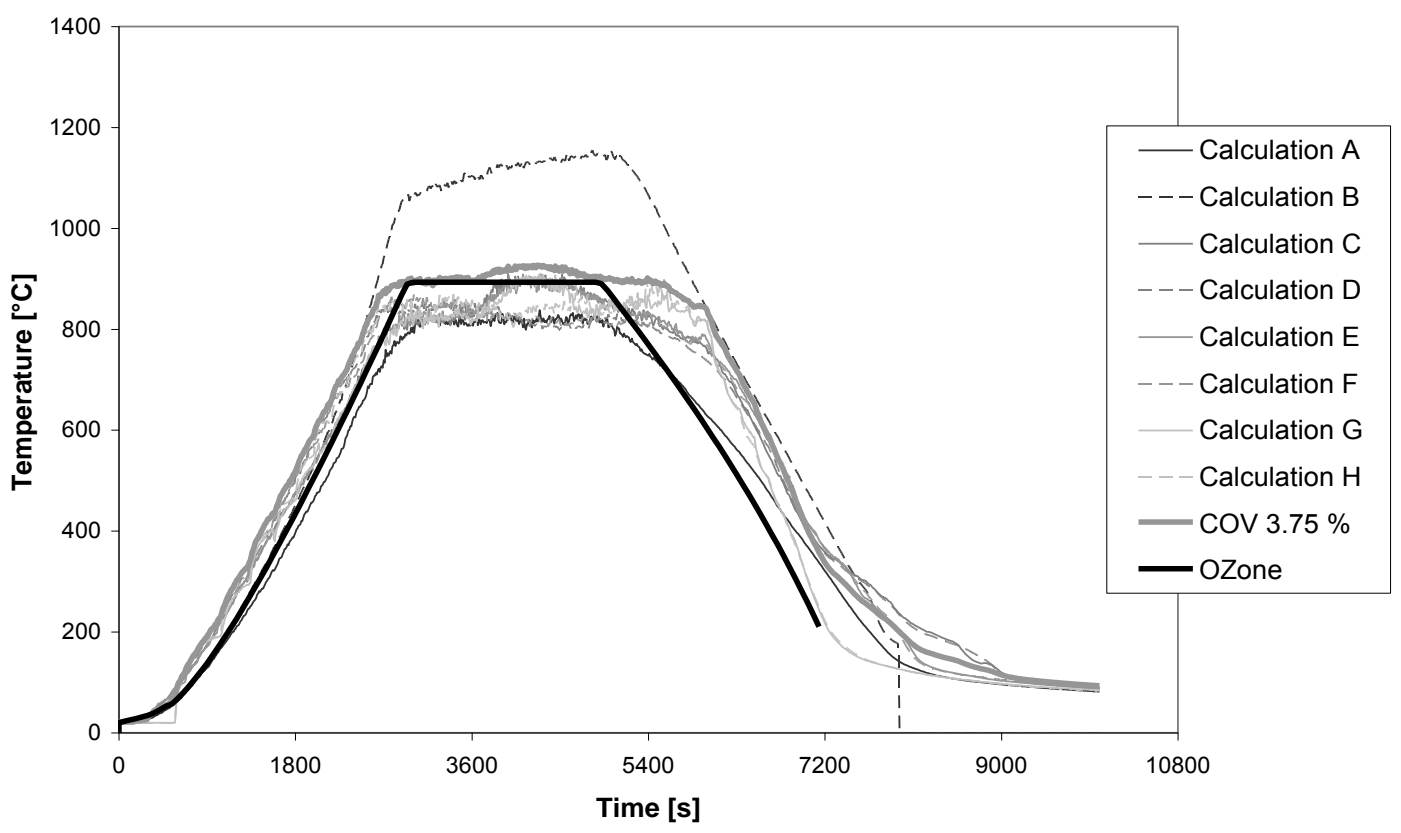

Fig. 10. The thick gray represents a time-temperature relation that will not be exceeded with a certainty of $95.8 \%$ based on the CFD calculations.

\section{CONCLUSIONS}

The study shows that the concept of travelling fires can be adapted to CFD calculations. From the structural fire design point of view, the results are within reasonable agreement of methods such as two-zone models and the possibility to extract a temperature based on probability gives a better foundation for arguing for or against a design case.

It is, however, important to develop the technique further concerning how to address more complex geometries than the one used in this study. The use of CFD calculations for structural design demands a lot from the user. Creating simple models for assessing temperatures in simple cases increases the possibility to use CFD as a design tool. Also by structuring the use of CFD for design makes the process more transparent and enables a better discussion about, and control of, the fire design.

This study shows that CFD gives a result well within the range of two-zone models for a simple geometry. The next step is to extract specific temperatures for load-bearing elements in various locations in the fire compartment.

\section{REFERENCES}

[1] Martinez de Aragón, J.J., Rey, F., and Chica, J.A., Part 4: DIFISEK - Software for fire design, LABEIN Technological Centre, Bilbao, Spain.

[2] Eurocode 1: Actions on structures - Part 1-2: General actions - Actions on structures exposed to fire, EN 1991-1-2, Brussels, Belgium, 2002.

[3] Barnett., C.R., (2002) BFD curve: a new empirical model for fire compartment temperatures, Fire Safety Journal 37: 437-463. http://dx.doi.org/10.1016/S0379-7112(02)00006-1

[4] Hägglund, B., "Simulating fires in natural and forced ventilated enclosures," FOA report C 206372.4, Stockholm, Sweden, 1986, 42 p. 
[5] Cadorin, J.F., and Franssen, J-M., (2003) A tool to design steel elements submitted to compartment fires - OZone V2. - Part 1: Pre- and post-flashover compartment fire model, Fire Safety Journal 38: 429-451. http://dx.doi.org/10.1016/S0379-7112(03)00014-6

[6] Peacock, R.D., Jones, W.J., Reneke, P.A., and Forney, G.P., "C-FAST - Consolidated Model of Fire Growth and Smoke Transport (Version 6) User's Guide”, National Institute of Standards and Technology Special Publication 1041, Gaithersburg, MD, 2008, 110 p.

[7] Sunder, S.S., "Final Report on the Collapse of World Trade Center Towers," National Institute of Standards and Technology Report NCSTAR 1, Washington, Washington, D.C., 2005, 298 p.

[8] McGrattan, K., Klein, B., Hostikka, S., Floyd, J., "Fire Dynamics Simulator (Version 5) User's Guide," National Institute of Standards and Technology Special Publication 1019-5, U.S. Printing Office Washington, 2007, 200 p.

[9] Rein, G., Zhang, X., Williams, P., Hume, B., Heise, A., Jowsey, A., Lane B., and Torero, J.L., Multistory Fire Analysis for High-Rise Buildings, Proceedings of the $11^{\text {th }}$ International Interflam Conference, London, Sept. 2007. p. 605-616

[10] Stern-Gottfried, J., Rein, G., Torero, J.L., Travel Guide (Travelling Fires), Fire Risk Management, Nov 2009, pp. 12-16.

[11] Emmons, H.W., "Vent Flows," The SFPE Handbook of Fire Protection Engineering, (3 ${ }^{\text {rd }}$ ed.), DiNenno P.J. (ed.) National Fire Protection Association, Quincy, MA 02269, 2002, p. $2 / 32$.

[12] Law, A., Gillie, M., Stern-Gottfried, J., and Rein, G., (2011) The Influence of Travelling Fires on a Concrete Frame, Engineering $\quad$ Structures 1635-1642. http://dx.doi.org/10.1016/j.engstruct.2011.01.034

[13] McCaffrey, B.J., Quintiere, J.G., and Harkleroad, M.F., (1981) Estimating Room Temperatures and the Likelihood of Flashover Using Fire Test Data Correlations, Fire Technology 17: 98-119. http://dx.doi.org/10.1007/BF02479583

[14] Joint Committee of Structural Safety, JCSS Probabilistic Model Code, Zurich, 2001.

[15] Schleich, J.B., and Cajot, L-G., Valorisation Project: Natural Fire Safety Concept, Esch/Alzette, 2001. 